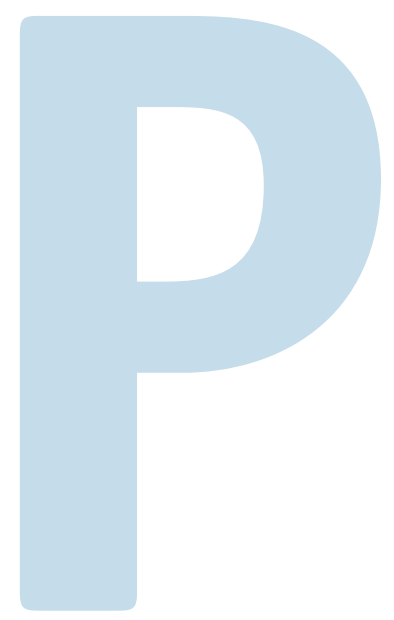

\section{PROCESSO DE HUMANIZAÇÃO NA ASSISTÊNCIA DE ENFERMAGEM À PARTURIENTE: REVISÃO INTEGRATIVA}

HUMANIZATION PROCESS IN NURSING CARE FOR THE PARTURIENT WOMAN: INTEGRATIVE REVIEW

PROCESO DE HUMANIZACIÓN EN ATENCIÓN DE ENFERMERÍA PARA LA PARTURIENTA: REVISIÓN

INTEGRADORA

Débora Ferreira Colares Alves ${ }^{1}$

Luana Feitosa Mourão 2

Antonio Dean Barbosa Marques ${ }^{3}$

July Grassiely de Oliveira Branco 4

Rochelle da Costa Cavalcante ${ }^{5}$

Rosalice Araújo de Sousa Albuquerque 6

\title{
RESUMO
}

Este estudo teve por objetivo conhecer o processo de humanização na assistência de enfermagem à parturiente. Trata-se Ede revisão integrativa da literatura realizada na base de dados Scientific Electronic Library Online Brasil (SciELO Br), utilizando os seguintes descritores: parto humanizado, cuidados de enfermagem e humanização da assistência. Foram analisados 21 artigos que obedeceram aos critérios de inclusão. As categorias formadas foram: "Humanização da assistência de enfermagem à parturiente" e "Práticas humanizadas ao parto". As evidências apontam que, para alcançar um atendimento qualificado $e$ humanizado, é necessário que ocorram as mais variadas mudanças. Essas modificações consistem em realizar uma reorganização dos cuidados, promover uma educação continuada dos trabalhadores de saúde, proporcionar uma estrutura física adequada e incorporar condutas não intervencionistas.

Palavras-chave: Parto Humanizado; Enfermagem; Gestante.

\footnotetext{
1. Enfermeira. Especialista em Enfermagem Obstétrica e Neonatal pelo Instituto Superior de Teologia Aplicada (Inta). Professora no Instituto Centro de Ensino Tecnológico do Ceará (Centec). Fortaleza (CE), Brasil.

2. Enfermeira. Especialista em Saúde da Mulher pela Universidade Cândido Mendes (Ucam). Hospital Distrital Dr. Evandro Ayres de Moura (HDEAM). Fortaleza (CE), Brasil.

3. Enfermeiro. Aluno de doutorado em Cuidados Clínicos em Enfermagem e Saúde na Universidade Estadual do Ceará (UECE). Bolsista da Coordenação de Aperfeiçoamento de Pessoal de Nível Superior (Capes). Fortaleza (CE), Brasil.

4. Enfermeira. Aluna de doutorado em Saúde Coletiva na Universidade de Fortaleza (Unifor). Fortaleza (CE), Brasil.

5. Enfermeira. Mestre em Saúde Coletiva pela Unifor. Professora no Centec. Fortaleza (CE), Brasil.

6. Enfermeira. Aluna de doutorado em Saúde Coletiva pela Unifor. Professora no Inta. Sobral (CE), Brasil.
} 


\section{ABSTRACT}

This study aimed to know the humanization process in nursing care for the parturient woman. This is an integrative literature review conducted on the database Scientific Electronic Library Online Brazil (SciELO Br), using the following descriptors: humanizing delivery, nursing care, and humanization of care. We analyzed 21 articles that met the inclusion criteria. The categories formed were: "Humanization of nursing care for the parturient woman" and "Humanizing practices at birth." Evidence indicates that, in order to achieve a good-quality and humanizing care, there is a need that the most varied changes take place. These changes consist in reorganizing care procedures, promoting continued education for health workers, providing an adequate physical structure, and incorporating non-interventionist behaviors.

Keywords: Humanizing Delivery; Nursing; Pregnant Woman.

\section{RESUMEN}

Este estudio tuvo como objetivo conocer el proceso de humanización en la atención de enfermería para la parturienta. Esta es una revisión integradora de la literatura realizada en la base de datos Scientific Electronic Library Online Brasil (SciELO Br), utilizando los siguientes descriptores: parto humanizado, atención de enfermería y humanización de la atención. Se analizaron 21 artículos que cumplían con los criterios de inclusión. Las categorías formadas fueron: "Humanización de la atención de enfermería para la parturienta" y "Prácticas humanitarias al parto". Las evidencias indican que, para lograr una atención humanizada y de buena calidad, es necesario que se produzcan los más variados cambios. Estos cambios consisten en reorganizar los procedimientos de atención, promover la educación continua para los trabajadores de la salud, proporcionar una estructura física adecuada e incorporar comportamientos no intervencionistas.

Palabras clave: Parto Humanizado; Enfermería; Mujer Embarazada.

\section{INTRODUÇÃO}

0 parto constitui momento único na vida da mulher, logo, pode ser lembrado pelas parturientes como uma grande alegria ou uma experiência extremamente dolorosa ${ }^{1}$.

A ideia central do parto humanizado é possibilitar que a mãe dê o filho à luz na forma natural dos acontecimentos, ou seja, seguindo o ritmo e as especificidades do corpo de cada mulher, com o mínimo de intervenções nesse processo de nascimento por parte dos profissionais da saúde 2 .

A assistência ao parto vem sofrendo modificações, tanto no que tange à conduta dos profissionais que a realizam como no entendimento da população acerca do assunto e a forma como são resolvidos os casos em que são desnecessárias intervenções. A mulher, que antes era protagonista da assistência, hoje é objeto - o parto deixou de ser considerado um processo fisiológico, o que descaracteriza a ideia de humanização ${ }^{3}$.

0 cuidado humanizado à parturiente é fruto do relacionamento entre os profissionais da saúde e a própria usuária do serviço - decorre da compreensão do fenômeno vivenciado pelo outro, pois o trabalho de parto e o parto são imprescindíveis para a mulher se tornar mãe $\mathrm{e}^{4}$.

Dessa forma, a humanização da assistência no momento do nascimento implica mudança de atitudes e de rotinas. Essa busca pela homeostasia da vida extrauterina é concretizada por meio de práticas assistenciais que garantem a integridade física e psíquica desse ser frágil que demanda cuidados. Logo, esse processo implica relações afetuosas e intervenções realmente necessárias ${ }^{5}$.

A assistência à reprodução, além dos fatores econômicos e sociais, é essencial para assegurar a saúde e a vida das mulheres no momento da reprodução, bem como para garantir uma vida sem limitações ao recém-nascido. Portanto, a redução da mortalidade materna e neonatal está diretamente ligada aos cuidados durante a gestação, o parto e 0 puerpério ${ }^{6}$.

A atenção humanizada suscita muitos significados ${ }^{7}$. A valorização dos aspectos culturais e sociais e, principalmente, da autonomia da mulher são imprescindíveis nesse processo, bem como a manutenção de condutas de suporte físico e emocional à parturiente, com práticas não invasivas, como: estímulo à deambulação, mudança de posição e uso da água para relaxamento. Somam-se a isso os vínculos afetivos entre mãe, família e bebê - a participação familiar deve ser estimulada.

0 interesse para a realização deste estudo surgiu durante a atuação de um dos membros de nosso grupo de pesquisa como enfermeira obstetra em hospital especializado em saúde da mulher. Por meio de atividades em contato com as parturientes, percebeu-se a importância da prevenção de complicações à parturiente e ao recém-nascido no momento 
do trabalho de parto, garantindo a eles o menor número possível de intervenções no pós-parto.

Com base nisso, adotamos a seguinte questão de pesquisa: como ocorre o processo de humanização da assistência de enfermagem durante o parto? Assim, este estudo teve por objetivo conhecer o processo de humanização na assistência de enfermagem à parturiente.

\section{METODOLOGIA}

Trata-se de revisão integrativa da literatura. Esse tipo de pesquisa sugere o estabelecimento de critérios delimitados sobre coleta de dados e análise e apresentação dos resultados desde o início, a partir de um protocolo previamente elaborado e validado. Adotaram-se as seguintes etapas: 1) identificação do tema e seleção da hipótese ou questão de pesquisa para a elaboração da revisão integrativa; 2) estabelecimento de critérios para inclusão e exclusão de estudos (amostragem ou busca na literatura); 3) definição das informações a extrair dos estudos selecionados (categorização dos estudos); 4) avaliação dos estudos incluídos na revisão integrativa; 5) interpretação dos resultados; e 6) apresentação da revisão (síntese do conhecimento) $)^{8,9}$.

Esta revisão enfocou artigos científicos na área da saúde por meio da base de dados Scientific Electronic Library Online Brasil (SciELO Br), em julho e agosto de 2015, utilizando os seguintes descritores: "parto humanizado", "cuidados de enfermagem" e “humanização da assistência".

Foram identificados 37 artigos. Os critérios de inclusão: artigos publicados na base de dados selecionada; artigos que abordassem a temática do estudo; artigos com data de publicação entre 2006 e 2014; e artigos disponíveis na íntegra em língua portuguesa. Após a leitura exploratória dos resumos, 21 artigos se mostraram em consonância com a temática - estes foram lidos na íntegra, a fim de determinar as informações de maior interesse para a pesquisa.

Os artigos selecionados são apresentados em quadro e caracterizados quanto a título, periódico, ano de publicação e objetivo(s). Com base na sua leitura integral, as informações foram agrupadas nas seguintes categorias: “Humanização da assistência de enfermagem à parturiente" e "Práticas humanizadas ao parto".

\section{RESULTADOS E DISCUSSÃO}

Os 21 artigos selecionados na SciELO Br foram caracterizados após sua leitura integral (Quadro 1).

Quadro 1 - Caracterização dos artigos selecionados na SciELO Br. Fortaleza, 2015.

\begin{tabular}{|c|c|c|c|}
\hline Título & Periódico & Ano & Objetivo(s) \\
\hline $\begin{array}{l}\text { Centro de parto normal } \\
\text { e assistência obstétrica } \\
\text { centrada nas necessidades da } \\
\text { parturiente }^{10}\end{array}$ & $\begin{array}{l}\text { Revista da Escola de } \\
\text { Enfermagem da USP }\end{array}$ & 2006 & $\begin{array}{l}\text { Estabelecer uma reflexão sobre a humanização na } \\
\text { assistência à saúde. }\end{array}$ \\
\hline $\begin{array}{l}\text { A humanização na assistência } \\
\text { à saúde }{ }^{11}\end{array}$ & $\begin{array}{l}\text { Revista Latino- } \\
\text { Americana de } \\
\text { Enfermagem }\end{array}$ & 2006 & $\begin{array}{l}\text { Divulgar a proposta de substituição da expressão } \\
\text { "assistência humanizada ao parto" por "assistência } \\
\text { obstétrica centrada nas necessidades da parturiente" e } \\
\text { discorrer como essa assistência é prestada no Centro de } \\
\text { Parto Normal do Hospital Geral de Itapecerica da Serra(SP). }\end{array}$ \\
\hline $\begin{array}{l}0 \text { significado dado pelo } \\
\text { profissional de saúde para } \\
\text { trabalho de parto e parto } \\
\text { humanizado }{ }^{12}\end{array}$ & $\begin{array}{l}\text { Acta Paulista de } \\
\text { Enfermagem }\end{array}$ & 2008 & $\begin{array}{l}\text { Compreender o significado que o profissional de saúde } \\
\text { que atende a parturiente atribui ao trabalho de parto e ao } \\
\text { parto humanizado. }\end{array}$ \\
\hline $\begin{array}{l}\text { Práticas de atenção ao parto e } \\
\text { os desafios para humanização } \\
\text { do cuidado em dois hospitais } \\
\text { vinculados ao Sistema Único } \\
\text { de Saúde em município da } \\
\text { Região Sul do Brasil }{ }^{13}\end{array}$ & $\begin{array}{l}\text { Cadernos de Saúde } \\
\text { Pública }\end{array}$ & 2008 & $\begin{array}{l}\text { Caracterizar a assistência hospitalar ao parto e identificar } \\
\text { obstáculos e aspectos facilitadores para a implantação do } \\
\text { cuidado humanizado. }\end{array}$ \\
\hline
\end{tabular}

70 - SANARE, Sobral - V.16 n.02,p.68-76, Jul./Dez. - 2017 


\begin{tabular}{|c|c|c|c|}
\hline Título & Periódico & Ano & Objetivo(s) \\
\hline $\begin{array}{l}0 \text { papel da equipe de saúde no } \\
\text { cuidado e conforto no trabalho } \\
\text { de parto e parto: opinião de } \\
\text { puérperas }^{14}\end{array}$ & $\begin{array}{c}\text { Texto \& Contexto } \\
\text { Enfermagem }\end{array}$ & 2008 & $\begin{array}{l}\text { Apresentar o papel da equipe de saúde, segundo a opinião } \\
\text { das mulheres, quanto aos métodos utilizados para seu } \\
\text { cuidado e conforto durante o trabalho de parto e o parto. }\end{array}$ \\
\hline $\begin{array}{l}\text { Humanização: a essência } \\
\text { da ação técnica e ética nas } \\
\text { práticas de saúde }{ }^{15}\end{array}$ & $\begin{array}{c}\text { Revista Brasileira de } \\
\text { Educação Médica }\end{array}$ & 2009 & $\begin{array}{l}\text { Discutir o surgimento da humanização no contexto } \\
\text { histórico e cultural de nossa época no momento em que a } \\
\text { sociedade pós-moderna passa por uma revisão de valores } \\
\text { culturais. }\end{array}$ \\
\hline $\begin{array}{l}\text { A enfermeira obstétrica: } \\
\text { agente estratégico na } \\
\text { implantação de práticas } \\
\text { do modelo humanizado em } \\
\text { maternidades }{ }^{16}\end{array}$ & $\begin{array}{c}\text { Revista Enfermagem } \\
\text { UERJ }\end{array}$ & 2009 & $\begin{array}{c}\text { Analisar as estratégias utilizadas para implantar o modelo } \\
\text { humanizado na Maternidade Municipal Leila Diniz, no Rio } \\
\text { de Janeiro. }\end{array}$ \\
\hline $\begin{array}{l}\text { Participação do acompanhante } \\
\text { na humanização do parto e } \\
\text { sua relação com a equipe de } \\
\text { saúde }^{17}\end{array}$ & $\begin{array}{l}\text { Revista Eletrônica } \\
\text { de Enfermagem }\end{array}$ & 2010 & $\begin{array}{l}\text { Refletir sobre a participação do acompanhante na } \\
\text { humanização do parto e nascimento e sobre sua interface } \\
\text { com a equipe de saúde. }\end{array}$ \\
\hline $\begin{array}{l}\text { Assistência ao parto na } \\
\text { maternidade: representações } \\
\text { sociais de mulheres assistidas } \\
\text { e profissionais de saúde }{ }^{18}\end{array}$ & $\begin{array}{c}\text { Psicologia: Reflexão } \\
\text { e Crítica }\end{array}$ & 2010 & $\begin{array}{l}\text { Investigar quais são as representações sociais de mulheres } \\
\text { assistidas e profissionais da saúde sobre a assistência ao } \\
\text { parto na maternidade e comparar as representações sociais } \\
\text { dos dois grupos. }\end{array}$ \\
\hline $\begin{array}{l}\text { As práticas humanizadas } \\
\text { desenvolvidas por enfermeiras } \\
\text { obstétricas na assistência ao } \\
\text { parto hospitalar }{ }^{19}\end{array}$ & $\begin{array}{l}\text { Revista Eletrônica } \\
\text { de Enfermagem }\end{array}$ & 2010 & $\begin{array}{c}\text { Discutir as práticas incorporadas e desenvolvidas por } \\
\text { enfermeiras desde a implantação do modelo humanizado de } \\
\text { assistência ao parto. }\end{array}$ \\
\hline $\begin{array}{l}\text { Reflexões sobre a assistência } \\
\text { de enfermagem prestada à } \\
\text { parturiente }{ }^{20}\end{array}$ & $\begin{array}{c}\text { Revista Brasileira de } \\
\text { Enfermagem }\end{array}$ & 2010 & $\begin{array}{l}\text { Identificar o estado da arte da produção publicada } \\
\text { sobre atuação da enfermeira obstétrica no processo do } \\
\text { nascimento, contribuir para futuras investigações e auxiliar } \\
\text { nas reflexões sobre essa temática. }\end{array}$ \\
\hline $\begin{array}{l}\text { Desempenho de indicadores } \\
\text { de processo do Programa de } \\
\text { Humanização do Pré-Natal e } \\
\text { Nascimento no Brasil: uma } \\
\text { revisão sistemática }{ }^{21}\end{array}$ & $\begin{array}{c}\text { Cadernos de Saúde } \\
\text { Pública }\end{array}$ & 2011 & $\begin{array}{l}\text { Compilar os dados nacionais sobre o acompanhamento pré- } \\
\text { natal de acordo com as metas do Programa de Humanização } \\
\text { do Pré-Natal e do Nascimento (PHPN), utilizando como } \\
\text { método de obtenção dos dados o próprio programa } \\
\text { computacional SisPrenatal ou outras fontes. }\end{array}$ \\
\hline $\begin{array}{l}\text { Atenção humanizada ao parto } \\
\text { de adolescentes: análise das } \\
\text { práticas desenvolvidas em um } \\
\text { centro obstétrico }{ }^{22}\end{array}$ & $\begin{array}{c}\text { Revista Brasileira de } \\
\text { Enfermagem }\end{array}$ & 2011 & $\begin{array}{l}\text { Analisar as práticas desenvolvidas na assistência } \\
\text { à parturiente adolescente, a partir do relato dos } \\
\text { trabalhadores da saúde e da pesquisa documental } \\
\text { dos registros existentes, em um centro obstétrico de } \\
\text { um hospital universitário, com base na proposta de } \\
\text { humanização do parto preconizada pelo Ministério da } \\
\text { Saúde. }\end{array}$ \\
\hline $\begin{array}{l}\text { Ações educativas durante } \\
\text { a assistência pré-natal: } \\
\text { percepção de gestantes } \\
\text { atendidas na rede básica de } \\
\text { Maringá-PR }\end{array}$ & $\begin{array}{l}\text { Revista Eletrônica } \\
\text { de Enfermagem }\end{array}$ & 2012 & $\begin{array}{c}\text { Conhecer a percepção de gestantes usuárias da rede básica } \\
\text { de saúde de Maringá (PR) sobre educação em saúde e como } \\
\text { ela ocorre. }\end{array}$ \\
\hline
\end{tabular}




\begin{tabular}{|c|c|c|c|}
\hline Título & Periódico & Ano & Objetivo(s) \\
\hline $\begin{array}{l}\text { Sistematização da assistência } \\
\text { de enfermagem em centro } \\
\text { obstétrico }{ }^{24}\end{array}$ & $\begin{array}{c}\text { Revista Brasileira de } \\
\text { Enfermagem }\end{array}$ & 2012 & $\begin{array}{l}\text { Propor um protocolo para a sistematização da assistência } \\
\text { de enfermagem para parturientes no centro obstétrico de } \\
\text { um hospital público em Recife. }\end{array}$ \\
\hline $\begin{array}{l}\text { A humanização da assistência } \\
\text { ao parto na percepção de } \\
\text { estudantes de medicina }{ }^{25}\end{array}$ & $\begin{array}{c}\text { Revista Brasileira de } \\
\text { Educação Médica }\end{array}$ & 2012 & $\begin{array}{l}\text { Verificar a concepção de parto humanizado na perspectiva } \\
\text { de estudantes de medicina. }\end{array}$ \\
\hline $\begin{array}{l}\text { A humanização do cuidado no } \\
\text { pré-parto e parto }{ }^{26}\end{array}$ & $\begin{array}{l}\text { Revista Digital } \\
\text { Fapam }\end{array}$ & 2012 & $\begin{array}{l}\text { Obter conhecimento sobre a assistência que deve ser } \\
\text { prestada à mulher no período pré-parto e parto, após a } \\
\text { implantação da Política Nacional de Humanização (PNH), } \\
\text { conhecer medidas preconizadas pelo Sistema Único } \\
\text { de Saúde (SUS) quanto ao PHPN e desvendar aspectos } \\
\text { históricos do parto e informar sobre a implantação da } \\
\text { assistência humanizada no parto. }\end{array}$ \\
\hline $\begin{array}{l}0 \text { discurso e a prática do parto } \\
\text { humanizado de adolescentes }{ }^{27}\end{array}$ & $\begin{array}{l}\text { Texto \& Contexto } \\
\text { Enfermagem }\end{array}$ & 2013 & $\begin{array}{c}\text { Conhecer as práticas de atenção ao parto desenvolvido } \\
\text { pelos profissionais da saúde no cuidado à parturiente } \\
\text { adolescente. }\end{array}$ \\
\hline $\begin{array}{l}\text { Narrativas de mulheres sobre } \\
\text { a assistência recebida em um } \\
\text { centro de parto normal }{ }^{28}\end{array}$ & $\begin{array}{l}\text { Cadernos de Saúde } \\
\text { Pública }\end{array}$ & 2013 & $\begin{array}{l}\text { Explorar a experiência relativa à assistência ao parto } \\
\text { recebida em um centro de parto normal. }\end{array}$ \\
\hline $\begin{array}{l}\text { A contribuição do } \\
\text { acompanhante para a } \\
\text { humanização do parto e } \\
\text { nascimento: percepções de } \\
\text { puérperas }^{29}\end{array}$ & Escola Anna Nery & 2014 & $\begin{array}{l}\text { Investigar a contribuição do acompanhante durante o parto } \\
\text { e o nascimento, na perspectiva das puérperas. }\end{array}$ \\
\hline $\begin{array}{l}\text { Intervenções obstétricas } \\
\text { durante o trabalho de parto e } \\
\text { parto em mulheres brasileiras } \\
\text { de risco habitual }{ }^{30}\end{array}$ & $\begin{array}{l}\text { Cadernos de Saúde } \\
\text { Pública }\end{array}$ & 2014 & $\begin{array}{l}\text { Descrever as boas práticas de atenção ao parto e as } \\
\text { intervenções obstétricas realizadas em mulheres de } \\
\text { risco obstétrico habitual que pariram em uma amostra } \\
\text { representativa de hospitais brasileiros com } \geq 500 \text { partos/ } \\
\text { ano. }\end{array}$ \\
\hline
\end{tabular}

Fonte: Elaborado pelos autores.

As informações apresentadas no Quadro 1 originaram as categorias discutidas a seguir: "Humanização da assistência de enfermagem à parturiente" e "Práticas humanizadas ao parto".

\section{Humanização da assistência de enfermagem à parturiente}

0 Movimento pela Humanização do Parto e Nascimento (MHPN) surgiu diante do uso irracional da tecnologia no setor saúde, que vem causando mais danos do que benefícios à mulher e ao bebê e constitui uma preocupação que abrange, além de aspectos relativos à saúde pública, como a redução da taxa de cesáreas e da mortalidade materna, o binômio mãe-filho ${ }^{19}$.

Em 2000, o Ministério da Saúde implantou em todo o país
- Programa de Humanização do Pré-Natal e do Nascimento (PHPN) - além da meta do atendimento humanizado no modelo da atenção integral, o PHPN incluía a necessidade de melhorar as condições de atendimento às gestantes na rede pública de saúde, para diminuir a mortalidade materna e perinatal ${ }^{21}$.

0 PHPN foi substituído por uma perspectiva transversal, constituindo uma política de assistência e não mais um programa específico, denominada Política Nacional de Humanização (PNH) - que mudou o patamar de alcance da humanização dos hospitais para toda a rede do Sistema Único de Saúde (SUS) ${ }^{15}$.

Nessa perspectiva, o termo "humanização" vem sendo utilizado com frequência no setor saúde, como ilustra o Quadro 2. 
Quadro 2 - Características dos artigos segundo o significado de humanização. Fortaleza, 2015.

\section{Significado de humanização}

Engloba uma série de diferentes aspectos referentes às ideias, aos valores e às práticas envolvendo as relações entre os profissionais da saúde, os pacientes, os familiares e os acompanhantes, incluindo os procedimentos de rotina do serviço e a distribuição de responsabilidades dentro dessa equipe ${ }^{10}$.

Processo amplo, demorado e complexo, ao qual se oferecem resistências, pois envolve mudanças de comportamento, que sempre despertam insegurança e resistência. É claro que a não adesão envolve, além da relação entre 0 paciente e 0 profissional, fatores relacionados aos pacientes, às doenças, aos tratamentos, à instituiçã $0^{11}$.

É dar às mulheres o que thes é de direito: um atendimento seguro, acolhedor e que respeite suas necessidades físicas, emocionais, psicológicas, sociais e espirituais, independente do profissional que dela cuide ou da instituição onde esta se encontre ${ }^{12}$.

Promover um cuidado promotor de conforto, apoio, confiança, segurança física e emocional, conduzindo a mulher no curso do trabalho de parto ${ }^{14}$.

Fundamenta-se no respeito e na valorização da pessoa humana e constitui um processo que visa à transformação da cultura institucional por meio da construção coletiva de compromissos éticos e de métodos para ações de atenção à saúde e de gestão dos serviços ${ }^{15}$.

Está pautada no diálogo com a mulher, na inclusão do pai no parto, além da busca por melhoria da relação entre a instituição hospitalar e seus consumidores ${ }^{17}$.

É aquela que considera a mulher como protagonista nesse momento e onde o profissional está apto a desenvolver o suporte físico e emocional à parturiente, com a realização de práticas invasivas ${ }^{19}$.

Consiste na atenção voltada à mulher e à família, considerando a parturiente protagonista do evento, dando liberdade de escolha, favorecendo um ambiente acolhedor, proporcionando a presença do acompanhante e promovendo suporte físico e emocional ${ }^{20}$.

Pressupõe-se que a rede de cuidado integrada, com acolhimento e vínculo do usuário com o sistema de saúde e educação em saúde disponibilizada universalmente entre usuários e equipe multiprofissional, permitirá que o atendimento à gestante se torne mais eficaz, incluindo melhores estratégias de documentação da informação ${ }^{21}$.

Destaca-se como uma abordagem que vem sendo implementada com o objetivo de tornar o nascimento uma experiência positiva e satisfatória para a mulher e sua família ${ }^{25}$.

Visa, além da tentativa de despertar esse tipo de consciência, a valorizar a relação entre as pessoas, tentando fortalecer o vínculo do novo membro com a família ${ }^{26}$.

Reunir competência técnica e científica aos preceitos éticos, respeitando a individualidade do ser humano. É preciso melhorar o grau de informação das parturientes em relação às suas condições de saúde e aumentar sua autonomia, a fim de que façam escolhas adequadas em seu processo de parturição ${ }^{27}$.

Envolve um conjunto de conhecimentos, práticas e atitudes que objetivam promover parto e nascimento saudáveis, com garantia de que a equipe de saúde realize procedimentos comprovadamente benéficos para o binômio mãe-filho, evitando intervenções desnecessárias e preservando a privacidade, a autonomia e os direitos das mulheres ${ }^{29}$.

Fonte: Elaborado pelos autores.

0 princípio da humanização no campo obstétrico hospitalar está centrado em uma assistência menos intervencionista, mais emotiva e com respeito aos direitos sexuais e reprodutivos da mulher ${ }^{16}$.

A visão holística do enfermeiro obstetra associada ao processo de enfermagem favorece uma assistência individualizada à parturiente, fundamentada no conhecimento científico, fazendo com que ela se sinta parte de um processo natural que acompanha o ritmo de seu próprio corpo. A função do enfermeiro obstetra é colaborar com as forças naturais do parto, criando condições mais favoráveis para o nascimento, vivenciando a ciência, a natureza e a ética, promovendo, assim, modificações de comportamento de acordo com as respostas da parturiente ${ }^{24}$.

A definição do conceito de humanização é polissêmica, logo, compreende múltiplas facetas. Nessa ótica, torna-se imprescindível a valorização da dignidade humana, o exercício da ética e da promoção do cuidado baseada no respeito à individualidade. 0 que requer a colaboração e a participação dos profissionais da saúde e da instituição, de modo a promover um ambiente acolhedor e favorável à assistência humanizada à parturiente.

\section{Práticas humanizadas ao parto}

Por ser a gravidez um evento significativo na vida da mulher, é caracterizada como um período de mudanças físicas e emocionais que determinam o acompanhamento pré-natal, com prioridade do acolhimento à mulher, de respostas às dúvidas e de apoio em relação ao medo, às angústias, às fantasias ou à simples curiosidade de saber o que acontece com seu corpo ${ }^{23}$.

As primeiras civilizações atribuíram inúmeros significados culturais ao processo de nascimento. Dessa forma, historicamente, 
esse processo é um evento natural, de caráter íntimo e privado, constituindo experiência compartilhada entre as mulheres e seus familiares 20 .

Por muito tempo, as parteiras, curandeiras ou comadres exerceram a atividade de partejar. Eram pessoas familiarizadas que detinham o conhecimento sobre as manobras externas para facilitar o parto, conheciam a gravidez e o puerpério por experiência própria e exerciam o papel de confortar as mulheres. Assim, tinham a preferência das parturientes por razões psicológicas, humanitárias e devido ao tabu de mostrar os órgãos genitais 20 .

0 parto consiste em uma experiência única, de significância psicológica, que pode deixar marcas positivas ou negativas dependendo da experiência vivenciada pela mulher. Além de fisiológico, é um processo cheio de significados no qual a mulher deve ser protagonista ${ }^{24}$.

A humanização do parto constitui termo mais abrangente do que se imagina, pois envolve questões como legitimidade científica, política, financeira, epidemiológica, profissional e corporativa, além de proporcionar a participação da parturiente nas decisões sobre sua saúde ${ }^{26}$.

Algumas práticas humanizadas são a adoção de métodos não farmacológicos no alívio de dor, o respeito ao direito da parturiente de ter um acompanhante de sua escolha e a liberdade de movimentação durante o parto. Além disso, salienta-se que a parturiente é quem autoriza a realização do exame tocoginecológico e que o acompanhante recebe orientações sobre condutas e procedimentos, bem como estímulo à participação durante o trabalho de parto e o parto. Por fim, enfatiza-se que o modelo assistencial empregado nos chamados centros de parto normal gera resistências entre muitos dos profissionais da saúde - que têm dificuldade para aderir às mudanças no modo de prestar assistência à parturiente ${ }^{26}$.

Com base na proposta de humanização, o desenvolvimento de práticas na assistência à parturição prevê atitudes e comportamentos dos profissionais da saúde que contribuam para reforçar o caráter de atenção à saúde como um direito de todas as mulheres. Contudo, na realidade de muitos serviços de saúde, muitas das recomendações ainda não foram introduzidas ou encontram resistência para sua efetivação nos centros obstétricos 22 .

Para a implementação do cuidado com ações humanizadas, vale valorizar a dimensão subjetiva e social em todas as práticas de atenção e gestão no SUS, fortalecer o trabalho em equipe multiprofissional, fomentar a autonomia e o protagonismo dos sujeitos, fortalecer o controle social com caráter participativo em todas as instâncias gestoras do SUS, democratizar as relações de trabalho e valorizar os profissionais da saúde ${ }^{1}$.

Os artigos selecionados sugerem que humanizar

\section{...valorizar a \\ dimensão subjetiva \\ e social em todas as \\ práticas de atenção e \\ gestão no SUS.}

a assistência à parturiente significa proporcionar um ambiente acolhedor, onde se respeita a individualidade da parturiente e ela é tratada como protagonista do processo de parturição. Na realidade brasileira, a adesão à humanização na assistência ao parto ainda constitui um grande desafio, visto que apresenta novas propostas relacionadas às práticas assistenciais e uma reformulação na relação entre paciente e profissional da saúde.

\section{CONSIDERAÇÕES FINAIS}

Em relação às práticas humanizadas, as mais frequentes foram: acolhimento à parturiente, orientações acerca do trabalho de parto e permissão da presença do acompanhante ao lado da parturiente. Também se constatou a existência de elementos que dificultam a execução de tais práticas, como: resistência e despreparo de muitos profissionais da saúde no processo de parturição, deficiência da estrutura física hospitalar e desconhecimento da parturiente em relação aos seus direitos.

As evidências apontam que, para alcançar um atendimento qualificado e humanizado, é necessário que ocorram as mais variadas mudanças - essas modificações consistem na reorganização dos cuidados, na promoção de uma educação continuada dos trabalhadores da saúde, em uma estrutura física adequada e na incorporação de condutas não intervencionistas.

\section{CONTRIBUIÇÃO DOS AUTORES}

\section{Débora Ferreira Colares Alves e Antonio Dean Barbosa}

Marques contribuíram com o delineamento e a realização da pesquisa e a redação do manuscrito. Luana Feitosa Mourão contribuiu com a coleta de dados. July Grassiely de Oliveira Branco, Rochelle da Costa Cavalcante e Rosalice Araújo de Sousa Albuquerque contribuíram com a revisão crítica do manuscrito. 


\section{REFERÊNCIAS}

1. Sescato AC, Souza SRRK, Wall ML. Os cuidados não farmacológicos para alívio da dor no trabalho de parto: orientações da equipe de enfermagem. Cogitare Enferm [serial on the internet]. 2008 [cited 2017 Dec 12];13(4):58590. Available from: http://revistas.ufpr.br/cogitare/article/ viewFile/13120/8879

2. Fialho TC. 0 papel do enfermeiro no parto humanizado. Viçosa (MG): Evata; 2008.

3. Bessa LF, Mamede MV. Ação educativa: uma perspectiva para humanização do parto? Rev Baiana Enferm [serial on the internet]. 2010 [cited 2017 Dec 12];24(1-3):11-22. Available from: https://portalseer.ufba.br/index.php/enfermagem/ article/viewFile/5699/4119

4. Ferreira Júnior AR, Makuch MY, Osis MJMD, Barros NF. Percepções de profissionais de enfermagem sobre a humanização em obstetrícia. Sanare (Sobral, Online) [serial on the internet]. 2015 [cited 2017 Dec 15];14(2):27-35. Available from: https://sanare.emnuvens.com.br/sanare/ article/view/821/492

5. Souza TG, Gaíva MAM, Modes PSSA. A humanização do nascimento: percepção dos profissionais de saúde que atuam na atenção ao parto. Rev Gaúch Enferm [serial on the internet]. 2011 [cited 2017 Dec 15];32(3):479-86. Available from: http://www.scielo.br/pdf/rgenf/v32n3/07.pdf

6. Brasil. Manual dos comitês de mortalidade materna. Brasília (DF): Ministério da Saúde; 2009.

7. Dias MAB, Domingues RMSM. Desafios na implantação de uma política de humanização da assistência hospitalar ao parto. Ciênc Saúde Colet [serial on the internet]. 2005 [cited 2017 Dec 15];10(3):669-705. Available from: http://bhpelopartonormal.pbh.gov.br/estudos cientificos/ arquivos/desafios na_implantacao de uma_politica_de humanizacao da assistencia hospitalar ao parto.pdf

8. Mendes KDS, Silveira RCCP, Galvão CM. Revisão integrativa: método de pesquisa para a incorporação de evidências na saúde e na enfermagem. Texto \& Contexto Enferm [serial on the internet]. 2008 [cited 14 Jun 2014];17(4):758-64. Available from: http://www.scielo.br/scielo.php?script=sci arttext\&pid $=$ S0104-07072008000400018\&lng =en \&nrm =iso

9. Minayo MCS, Deslandes SF, Gomes R. Pesquisa social: teoria, método e criatividade. 29. ed. Petrópolis (RJ): Vozes; 2010.

10. Machado NXS, Praça NS. Centro de parto normal e assistência obstétrica centrada nas necessidades da parturiente. Rev ESC Enferm USP [serial on the internet]. 2006 [cited 2017 Dec 15];40(2):274-9. Available from: http://www.scielo.br/pdf/reeusp/v40n2/16.pdf

11. Oliveira BRG, Collet N, Viera CS. A humanização na assistência à saúde. Rev Latinoam Enferm [serial on the internet]. 2006 [cited 2017 Dec 15];14(2):277-84. Available from: http://www.scielo.br/pdf/rlae/v14n2/v14n2a19.pdf
12. Mabuchi AS, Fustinoni SM. 0 significado dado pelo profissional de saúde para trabalho de parto e parto humanizado. Acta Paul Enferm [serial on the internet]. 2008 [cited 2017 Dec 15];21(3):420-6. Available from: http:// www.scielo.br/pdf/ape/v21n3/pt_06.pdf

13. Nagahama EEI, Santiago SM. Práticas de atenção ao parto e os desafios para humanização do cuidado em dois hospitais vinculados ao Sistema Único de Saúde em município da Região Sul do Brasil. Cad Saúde Pública [serial on the internet]. 2008 [cited 2017 Dec 15];24(8):1859-68. Available from: http://www.scielo.br/pdf/csp/v24n8/14.pdf

14. Carraro TE, Knobel R, Frello AT, Gregório VRP, Grüdtner DI, Radünz V, et al. 0 papel da equipe de saúde no cuidado e conforto no trabalho de parto e parto: opinião de puérperas. Texto \& Contexto Enferm [serial on the internet]. 2008 [cited 2017 Dec 15];17(3):502-9. Available from: http:// www.scielo.br/pdf/tce/v17n3/a11v17n3.pdf

15. Rios IC. Caminhos da humanização na saúde: prática e reflexão. Rev. bras. educ. med. [serial on the internet]. 2009 [cited 2017 Dec 15];33(2):253-261. Available from: http:// www.scielo.br/pdf/rbem/v33n2/13.pdf

16. Progiantii JM, Mouta RJ0. A enfermeira obstétrica: agente estratégico na implantação de práticas do modelo humanizado em maternidades. Rev Enferm UERJ [serial on the internet]. 2009 [cited 2017 Dec 15];17(2):165-9. Available from: http://www.facenf.uerj.br/v17n2/v17n2a04.pdf

17. Longo CSM, Andraus LMS, Barbosa MA. Participação do acompanhante na humanização do parto e sua relação com a equipe de saúde. Rev Eletrônica Enferm [serial on the internet]. 2010 [cited 2017 Dec 15];12(2):386-91. Available from: http://www.revistas.ufg.br/index.php/fen/article/ view $/ 5266 / 6945$

18. Silveira SC, Camargo BV, Crepaldi MA. Assistência ao parto na maternidade: representações sociais de mulheres assistidas e profissionais de saúde. Psicol Reflex Crít [serial on the internet]. 2010 [cited 2017 Dec 15];23(1):1-10. Available from: http://www.scielo.br/pdf/prc/v23n1/ a02v23n1.pdf

19. Porfírio $A B$, Progianti JM, Souza DOM. As práticas humanizadas desenvolvidas por enfermeiras obstétricas na assistência ao parto hospitalar. Rev Eletrônica Enferm [serial on the internet]. 2010 [cited 2017 Dec 15];12(2):331-6. Available from: https://www.fen.ufg.br/revista/v12/n2/ v12n2a16.htm

20. Velho MB, Oliveira ME, Santos EKA. Reflexões sobre a assistência de enfermagem prestada à parturiente. Rev Bras Enferm [serial on the internet]. 2010 [cited 2015 0ct 4];63(4):652-9. Available from: http://www.scielo.br/pdf/ reben/v63n4/23.pdf

21. Andreucci CB, Cecatti JG. Desempenho de indicadores de processo do Programa de Humanização do Pré-Natal e Nascimento no Brasil: uma revisão sistemática. Cad Saúde Pública [serial on the internet]. 2011 [cited 2015 0ct 4];27(6):1053-64. Available from: http://www.scielo.br/ $\mathrm{pdf} / \mathrm{csp} / \mathrm{v} 27 \mathrm{n} 6 / 03 . \mathrm{pdf}$ 
22. Busanello J, Kerber NPC, Mendoza-Sassi RA, Mano PS, Susin LR0, Gonçalves BG. Atenção humanizada ao parto de adolescentes: análise das práticas desenvolvidas em um centro obstétrico. Rev Bras Enferm [serial on the internet]. 2011 [cited 2017 Dec 15];64(5):824-32. Available from: http://www.scielo.br/pdf/reben/v64n5/a04v64n5.pdf

23. Souza VB, Roecker S, Marcon SS. Ações educativas durante a assistência pré-natal: percepção de gestantes atendidas na rede básica de Maringá-PR. Rev Eletrônica Enferm [serial on the internet]. 2011 [cited 2017 Dec 15];13(2):199-210. Available from: https://www.fen.ufg.br/revista/v13/n2/ v13n2a06.htm

24. Santos RB, Ramos KS. Sistematização da assistência de enfermagem em centro obstétrico. Rev Bras Enferm [serial on the internet]. 2012 [cited 20150 ct 4];65(1):13-8. Available from: http://www.scielo.br/pdf/reben/v65n1/02.pdf

25. Rebello MTMP, Rodrigues Neto JF. A humanização da assistência ao parto na percepção de estudantes de medicina. Rev Bras Educ Méd. 2012;36(2):188-97. Available from: http://www.scielo.br/pdf/rbem/v36n2/06.pdf

26. Menezes MGB, Dias DFS. A humanização do cuidado no préparto e parto. Revista Digital Fapam [serial on the internet]. 2012 [cited 2017 Dec 15];(3):24-36. Available from: http://fapam.web797.kinghost.net/revista/volume 3/4\%20 Marisa \%20Daniella\%20-\%2024\%20A\%2036.pdf

27. Silva RC, Soares MC, Jardim VMR, Kerber NPC, Meincke SMK. 0 discurso e a prática do parto humanizado de adolescentes. Texto \& Contexto Enferm [serial on the internet]. 2013 [cited 2015 0ct 4];22(3):629-36. Available from: http://www.scielo.br/pdf/tce/v22n3/v22n3a08.pdf

28. Jamas MT, Hoga LAK, Reberte LM. Narrativas de mulheres sobre a assistência recebida em um centro de parto normal. Cad Saúde Pública [serial on the internet]. 2013 [cited 2015 0ct 4];29(12):2436-46. Available from: http://www.scielo. $\mathrm{br} / \mathrm{pdf} / \mathrm{csp} / \mathrm{v} 29 \mathrm{n} 12 / \mathrm{v} 29 \mathrm{n} 12 \mathrm{a} 09 . \mathrm{pdf}$

29. Dodou HD, Rodrigues DP, Guerreiro EM, Guedes MVC, Lago PN, Mesquita NS. A contribuição do acompanhante para a humanização do parto e nascimento: percepções de puérperas. Esc Anna Nery Rev Enferm [serial on the internet]. 2014 [cited 20150 ct 4];18(2):262-9. Available from: http://www. scielo.br/pdf/ean/v18n2/1414-8145-ean-18-02-0262.pdf

30. Leal MC, Pereira APE, Domingues RMSM, Filha MMT, Dias MAB, Nakamura-Pereira $M$, et al. Intervenções obstétricas durante 0 trabalho de parto e parto em mulheres brasileiras de risco habitual. Cad Saúde Pública [serial on the internet]. 2014 [cited 2015 0ct 4];30(Suppl 1):S17-S32. Available from: http://www.scielo.br/readcube/ epdf.php?doi=10.1590/0102-311X00151513\&pid=S0102$311 \times 2014001300005 \& p d f \_p a t h=c s p / v 30 s 1 / 0102-311 X-c s p-$ 30-s1-0017.pdf\&lang $=p t$

Recebido em 05/06/2017 Aprovado em 30/11/2017

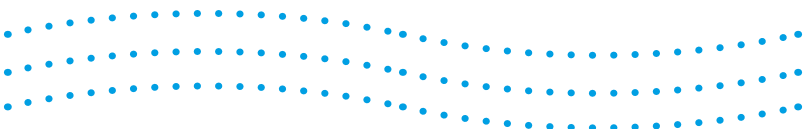

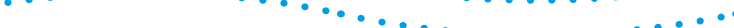

$\ldots \ldots \ldots \ldots \ldots \ldots \ldots \ldots \ldots$ $\ldots \ldots \ldots \ldots \ldots \ldots \ldots \ldots \ldots$ $\ldots \ldots \ldots \ldots \ldots \ldots$

$\ldots \ldots \ldots \ldots \ldots \ldots \ldots$ $\ldots \ldots \ldots \ldots \ldots \ldots \ldots$ $\ldots \ldots \ldots \ldots \ldots \ldots \ldots \ldots \ldots$ $\ldots \ldots \ldots \ldots \ldots \ldots$ $\ldots \ldots \ldots \ldots$ $\ldots \ldots \ldots \ldots \ldots \ldots \ldots \ldots$ $\ldots \ldots \ldots \ldots \ldots$

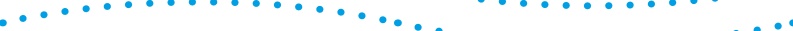
$\ldots \ldots \ldots \ldots \ldots \ldots \ldots \ldots \ldots \ldots$ 